\title{
Drying of binary thin film polymeric coatings: an experimental study
}

\author{
Jitendra Katariya ${ }^{1}$, Raj Kumar Arya ${ }^{2, *}$ \\ ${ }^{1}$ Jaypee University of Engineering \& Technology, M. Tech. Scholar, Department of Chemical Engineering, Guna, A.B. Road, \\ Guna, Raghogarh-473226, M.P., India, email: jkatariyache@gmail.com \\ ${ }^{2}$ Jaypee University of Engineering \& Technology, Assistant Professor, Department of Chemical Engineering, Guna, A. B. Road, \\ Raghogarh, Guna -473226, M.P., India, e-mail:raj.arya@juet.ac.in \\ "Corresponding author: e-mail: raj.arya@juet.ac.in
}

\begin{abstract}
Four binary polymer -solvent systems, poly(styrene)-tetrahydrofuran, poly(styrene) - p-xylene, poly(methyl methacrylate) - ethylbenzene and poly(methyl methacrylate) - tetrahydrofuran, systems have been studied. It has been observed that thicker coatings will retain a higher amount of the residual solvent as compared to thinner coatings. In the case of poly(styrene)-tetrahydrofuran coating residual solvent remaining within the coatings were $9.09 \%$ and $4.74 \%$ for the coatings of the thicknesses of 967 micron and 559 micron, respectively. Similar trends were also observed in the case of poly(methyl methacrylate)-ethylbenzene, poly(methyl methacrylate)-tetrahydrofuran, and poly(styrene)-p-xylene systems.
\end{abstract}

Keywords: Binary Coatings, Thin Films, Drying, Diffusion.

\section{INTRODUCTION}

Several polymer coatings such as adhesives, magnetic media, audio and video tapes are made by applying a polymer solution, made by dissolving a polymer in a solvent(s), on a moving followed by drying. Thin film polymeric coatings are made using thin film coating technology. Coatings are used in synthetic fibers, photographic films, and magnetic media etc. The final structure and the coating properties are governed by the proper drying conditions i.e. air flows, oven temperature and the drying time. Low quality, internal gradients, phase separations, non-uniformitities and stress related defects may occur due to improper drying conditions. Drying is the last and quality control step. Simultaneous heat and mass transfer operations occur during the course of drying of the volatile solvents from the coating.

Drying behavior of polymer solution coatings involves two steps, (i) transport of the solvent with the coating towards the surface, (ii) removal of the solvent from the surface. The resistance to drying due to the diffusional transport of the solvent within the coating is called internal resistance and the resistance to solvent removal due to evaporation at the surface and transport into the gas phase is called external resistance to drying. Internal diffusion becomes controlling factor at the later stage in drying of polymer coatings and determines the final solvent content with the coating. In the initial stages the rate of evaporation will be lower than or equal to the rate of diffusion of the solvent within the coating due to high initial concentration of the solvent with the coating. Diffusion in the polymeric coatings is a strong function of the solvent weight fraction within the coating. Therefore, in the beginning drying is externally controlled due to evaporation only. As the solvent departs from the coating, the rate controlling step for drying shifts from external mass transfer to internal mass transfer within the coating. Diffusion induced convection is responsible to move the solvents from the coating to the surface. Diffusion coefficient drops dramatically as the solvent concentration falls withhin the coating ${ }^{1}$.

Fick's law defines the flux of the solvent in a binary system to be proportional to the solvent concentration gradient. The mutual diffusion coefficient characterizes the solvent and polymer transport properties ${ }^{2-4}$.The selection of the coating technique depends on the application of the coating. Industrial polymeric coatings can be made by dipping, flow coating, and spraying. Some coatings are applied by brushing, rolling, printing, and silk screening 5 .

In industrial processes, a homogeneous polymer solution is applied on the substrate. Coatings are produced in the form of webs which are subjected to the multizone dryers that produce a thin sheet of some nonvolatile material on the substrate. A colloidal mixture of non-volatile solute and volatile solvent forming a homogeneous solution is used in the process. The loss of the solvent occurs due to evaporation from the surface. Jets of hot air may be blown from the top and bottom of the coating at an optimum temperature above the boiling point of the solvent but below the boiling point of the coating to avoid defects ${ }^{6}$. Drying conditions such as air flows, film thickness, relative humidity, temperature are responsible for final structure and properties of the coatings?

The aim of drying is to remove the solvent(s) from a wet coating to the desired levels without inducing any defects such as blisters, cracking and blush. Drying is usually accomplished in multi-zone dryers where in each zone hot air is blown over the coating. Many other dryer configurations exist in practice, which have been characterized by the heat transfer coefficient obtained in them ${ }^{8}$. In few configurations, the air flows only on the top side and parallel to the coating.

The air temperature and its flow rate constitute important operating conditions of a dryer. The conditions could change from one zone to the other to achieve the drying goals. Improper choice of the conditions could generate defects in the coatings during drying and lead to production losses. Price and Cairncross ${ }^{9}$ studied the effect of operating conditions on blister formation during drying in a single-zone dryer. They defined the bubble point temperature as the temperature at which the solvent partial pressure becomes equal to the ambient pressure. The bubble point temperature falls from the top of the coating to its bottom because the solvent concentration and, hence, its activity rises in that direction. They sta- 
ted that whenever the coating temperature exceeds the bubble point temperature, blisters are induced.

Earlier researchers ${ }^{\mathbf{9 - 1 5}}$ have reported the simulation study of binary coatings. This work deals with the experimental study of binary polymeric coatings using gravimetric analysis.

\section{EXPERIMENTAL SECTION}

Polymer films were made using solution casting mechanism. Polymer - solvent solutions were made in the leach proof bottles. Continuous manual shaking was done for $30 \mathrm{~min}$ four times a day for four weeks in order to get the homogeneous polymer-solvent solution. Four binary polymer-solvent systems were made: containing $10.24 \mathrm{wt} \%$ poly(styrene)(PS)-89.76 wt \% tetrahydrofuran(THF), $10.09 \mathrm{wt} \%$ poly(styrene)-89.91wt \% p-xylene, 9.87wt \% poly(methyl methacrylate)(PMMA)-90.13wt\% ethylbenzene(EB) and 10.04 wt \% poly(methyl methacrylate)-89.96wt\% tetrahydrofuran. All chemicals have been used without any further purification and are given in Table 1.

The weight of the empty sample holder was recorded and then a known amount of polymeric solution was poured into the cylindrical holder with the help of micropipette. For an instance, 177 micro liters PS - THF solution is needed to get a thickness of 967 microns. The cylindrical sample holders were 1000 microns deep with a diameter of 15000 microns. It was made of stainless steel. Mass transfer will take place only from the top into the air since the substrate is impermeable. However, heat transfer can take place both from the top and bottom sides. All the experiments were performed in the air conditioned room without any air flow. The average temperature of the room was maintained at $292 \pm 1 \mathrm{~K}$. As soon as the solution was poured into the holder, the mass of the sample holder and the polymer solution were recorded with time using Sartorius analytical weighing balance having the accuracy of $\pm 0.0001 \mathrm{~g}$. Instantaneous thickness of the coating was calculated from the instantaneous mass of the coating recorded from the weighing balance as follows:

Let the mass of the coating at any time be $m_{\text {coating }}$ having $m_{\text {polymer }}$ amount of the polymer in the beginning. The mass of the solvent within the coating at that instant, $m_{\text {solvent }}=m_{\text {coating }}-m_{\text {polymer }}$

The volume of the coating $V_{\text {coating }}=\frac{m_{\text {polymer }}}{\rho_{\text {polymer }}}+\frac{m_{\text {solvent }}}{\rho_{\text {solvent }}}$, assuming no volume change on mixing, instantaneous thickness of the coating,

$L=\frac{V_{\text {coating }}}{\text { cross sectional area of holder }}$

\section{RESULTS AND DISCUSSION}

Figure 1(a) shows the average concentration of THF with time in PS - THF coating. THF concentration fell Very rapidly due to a higher rate of evaporation and the process is externally mass transfer controlled. Later on, the mass transfer process becomes diffusion control
Table 1. List of chemicals used

\begin{tabular}{|l|c|c|c|}
\hline $\begin{array}{l}\text { Name of } \\
\text { Chemical }\end{array}$ & $\begin{array}{c}\text { Density, } \\
\mathrm{g} \mathrm{cm}^{-3}\end{array}$ & $\begin{array}{c}\text { Molecular } \\
\text { weight, } \\
\mathrm{g} \mathrm{mol}^{-1}\end{array}$ & Supplier \\
\hline PS & 1.05 & 192,000 & $\begin{array}{c}\text { SigmaAldrich, } \\
\text { Germany }\end{array}$ \\
\hline PMMA & 1.18 & 120,000 & $\begin{array}{c}\text { SigmaAldrich, } \\
\text { Germany }\end{array}$ \\
\hline THF & 0.886 & 72.11 & Merck, India \\
\hline EB & 0.866 & 106.17 & Merck, India \\
\hline$p$-xylene & 0.861 & 106.16 & Merck, India \\
\hline
\end{tabular}

within the coating. Diffusion in polymeric solution is the strong function of concentration. Therefore, the diffusion coefficient decreases significantly. Vrentas and Duda ${ }^{16}$ have studied the effect of solvent weight fraction on the diffusion coefficient and the results indicates that its value decreases by several orders of magnitude with the decrease in the solvent weight fraction. As the amount of tetrahydrofuran falls, the weight of coating will also decrease with time and after a certain period of time there will be no significant changes in the coating weight. Hence, drying will be shut off for practical purposes. Coating-gas interface moves towards the substrate due to the loss of solvent from the coating. In thicker coatings, top surface will get dried completely very soon and will have nearly pure polymer layer up to few microns only. This nearly pure polymer layer is transparent and looks like glass, therefore, it is called as the glassy layer in polymer coating nomenclature. This glassy layer will not allow any solvent evaporation from the coating. Hence, higher concentration of solvent in the thicker coating?

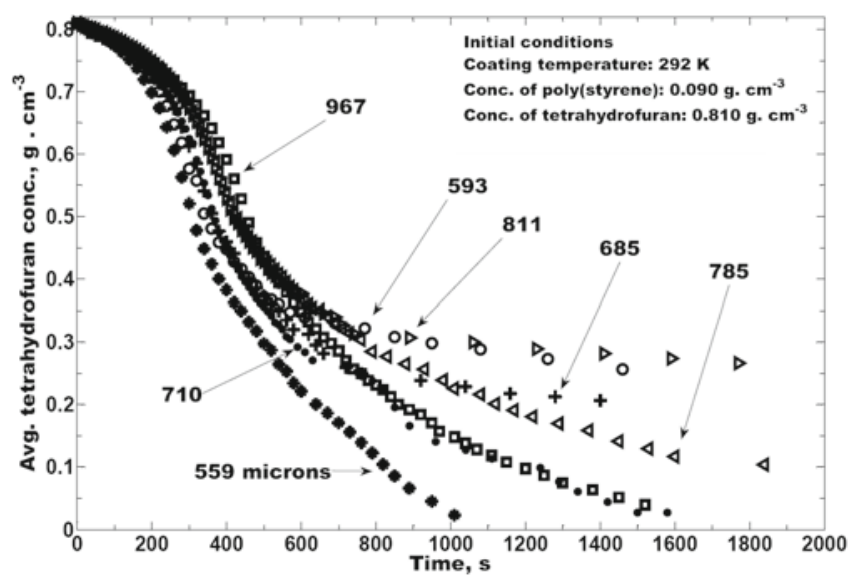

Figure 1a. Average concentration of THF with time in PS - THF coating

PS average concentration increased within the coating as the solvent is departing from coating as shown in Figure 1(b).

Figure 1(c) shows the percentage of residual solvent content of the coating. Hence, drying is shut off for practical purposes with time. Almost $90 \%$ solvent was removed during the initial 200-500 s. Up to $300 \mathrm{~s}$; drying behavior is nearly linear due externally controlled mass transfer. It is called the nearly constant rate period. The falling rate period has been observed from 300-600 s. Beyond $600 \mathrm{~s}$, there is no significant change in the residual solvent content of the coating.

PS - $p$-xylene, PMMA - THF and PMMA - EB have also been studied and similar trends have been observed as in the case of PS - THF system and are shown in 


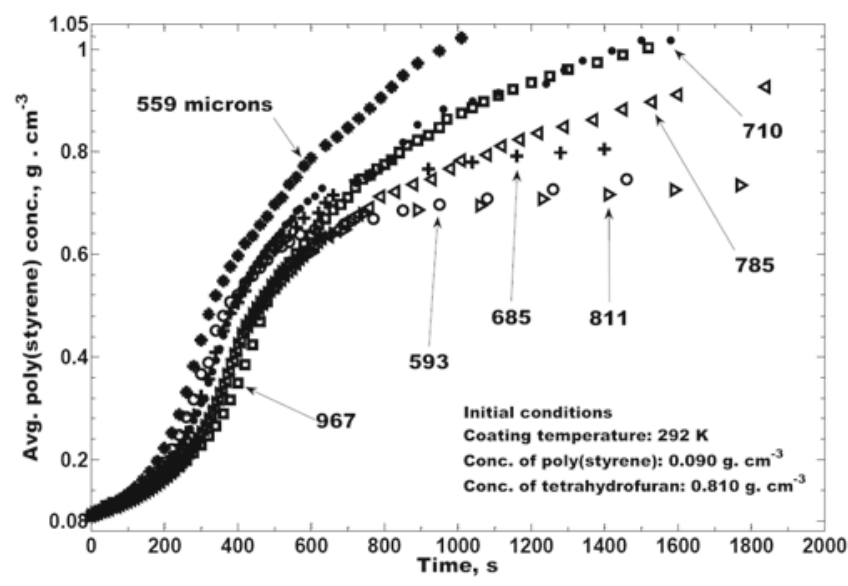

Figure 1b. Average concentration of PS with time in PS - THF coating

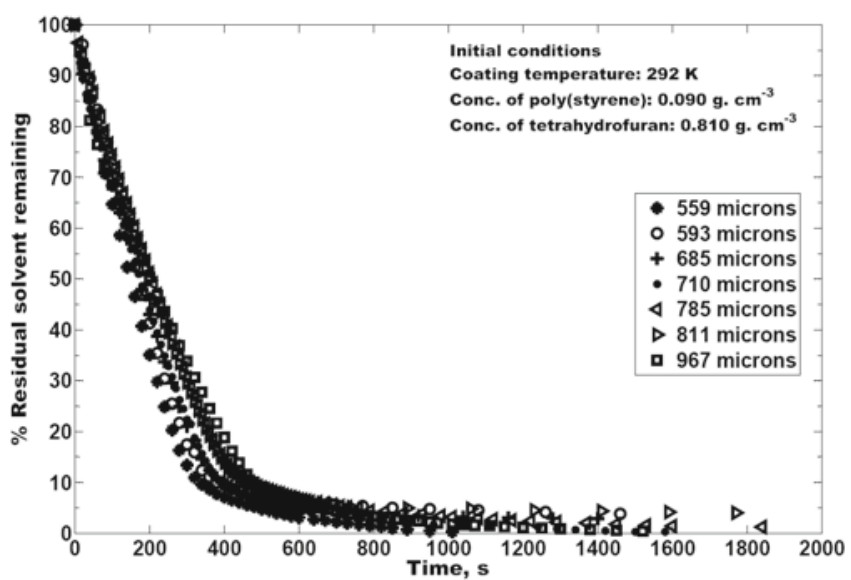

Figure 1c. Percentage of the residual solvent with time in PS THF coating

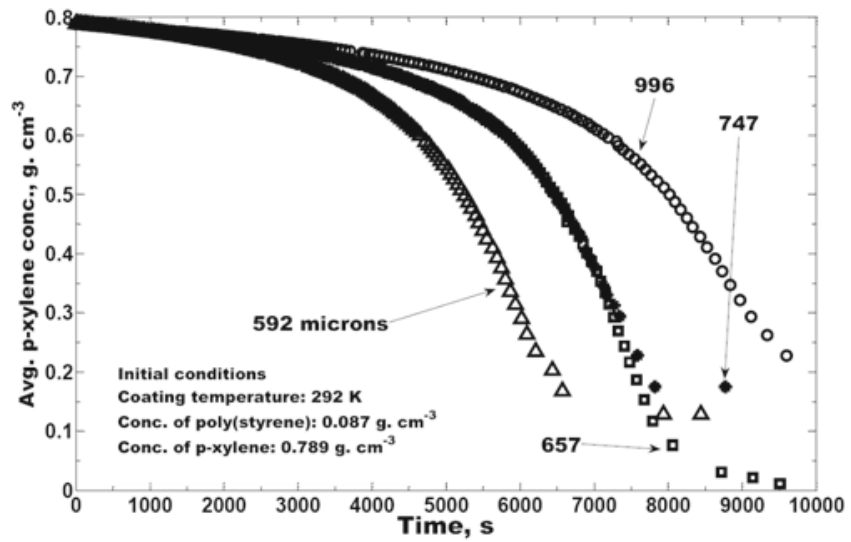

Figure 2a. Average concentration of $p$-xylene with time in PS- $p$-xylene coating

Figures 2, 3 and 4 (a), (b) and (c) respectively. There is a shift in the constant rate period due to high enthalpy of vaporization and low mass transfer coefficient of $p$-xylene.

According to free-volume theory ${ }^{2-3}$, diffusion in polymeric solution is a strong function of polymer and solvent jumping unit. Jumping unit is the size of polymer chain or solvent molecule which takes part in the diffusion transport. As the molecular weight becomes higher, the size of jumping units will be higher and hence a low diffusion coefficient. The low diffusion coefficient results in higher residual solvent and longer drying time. The effect of solvent and polymer jumping unit can be observed from Figure 1(c) and 2(c). Nearly 95\% solvent has been removed in 600s in PS - THF system as shown in Figure 1(c). However, in the case of PS $-p$-xylene

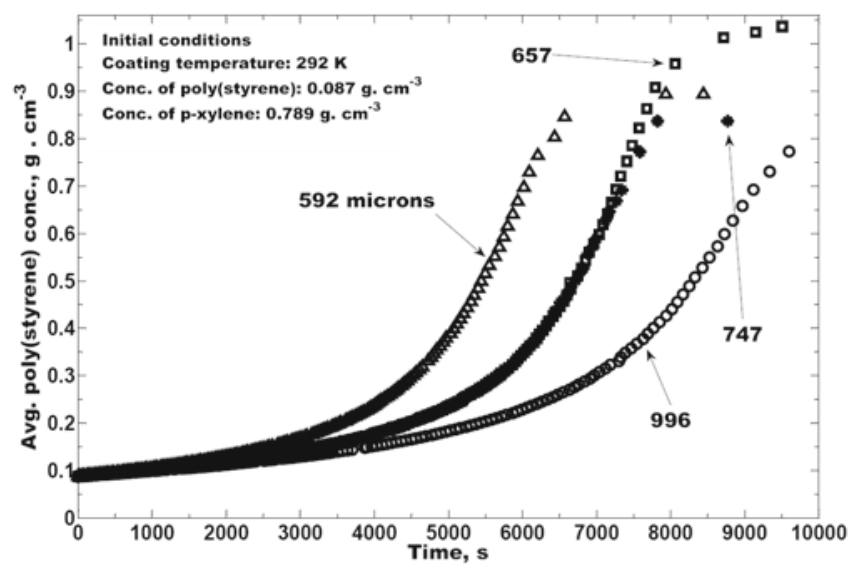

Figure 2b. Average concentration of PS with time in PS-p-xylene coating

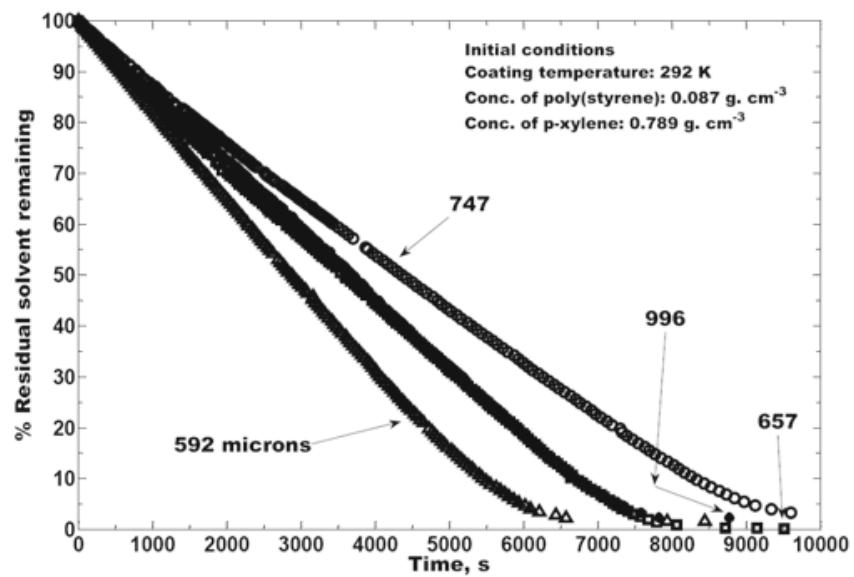

Figure 2c. Percentage of residual solvent remaining with time in PS $-p-$ xylene coating

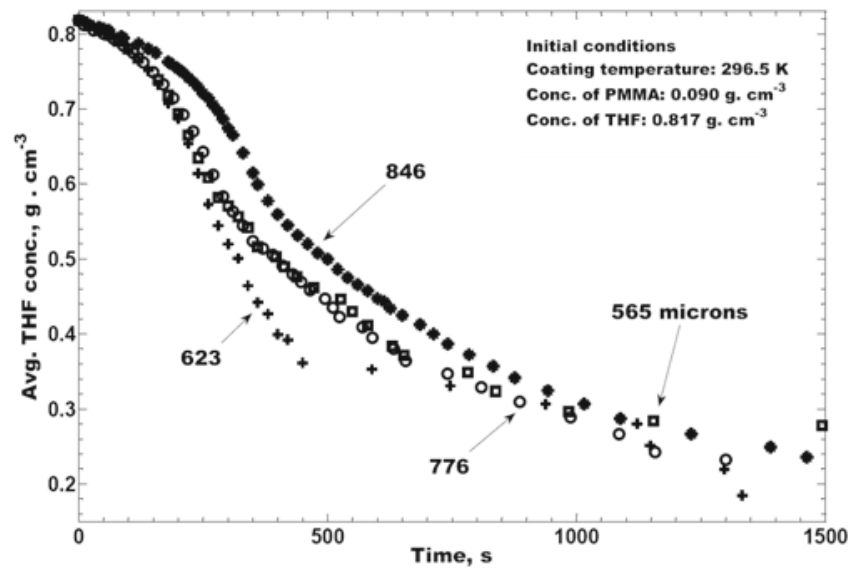

Figure 3a. Average concentration of THF with time in PMMA-THF coating

system, $95 \%$ of the solvent is removed in 6000 s as shown in Figure 2(c) for the same initial concentration of the solvent since the size of $p$-xylene jumping unit is larger then THF system ${ }^{17-18}$. Both experiments were performed under the same drying conditions. A similar observation have been made in the case of PMMA - THF and PMMA-EB systems. In PMMA - THF system, 95\% solvent has been removed in 500s while in the case of PMMA - EB system, 95\% solvent has been removed in 6000s as shown in Figure 3(c) and 4(c), respectively. The coating having high volatile solvent are drying faster and have less residual solvent as shown in Table 2.

Higher molecular weight solvents and polymers give a higher amount of residual solvent because higher mole- 


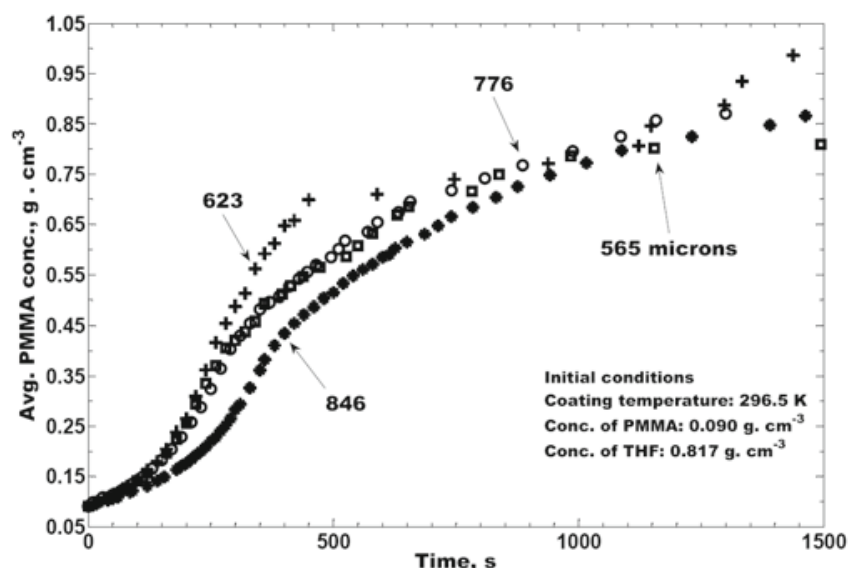

Figure 3b. Average concentration of PMMA with time in PMMA-THF coating

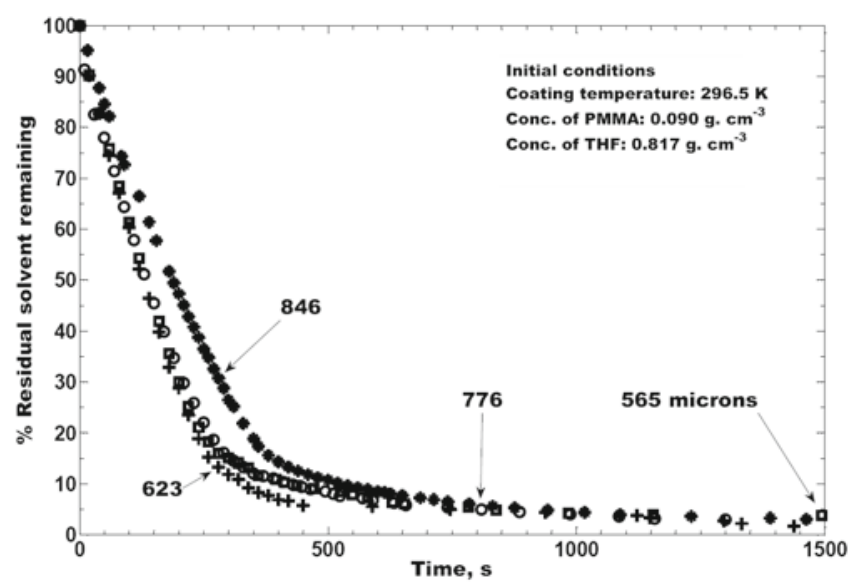

Figure 3c. Percentage of residual solvent remaining with time in PMMA-THF coating

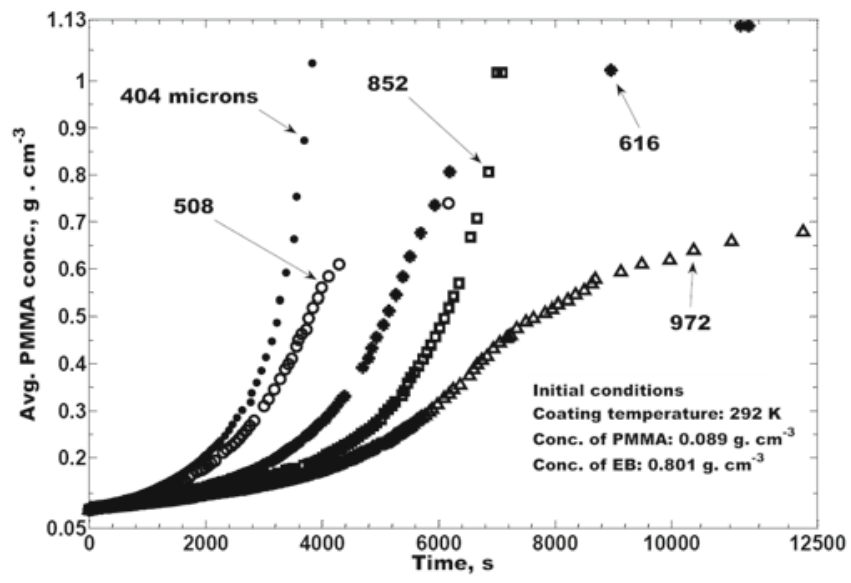

Figure 4a. Average concentration of PMMA with time in PMMAEB coating

cular weight solvents will have lower diffusion coefficient due to larger jumping unit as shown in Table 3.

Thicker coating will retain a higher amount of residual solvent within the coating due to glassy layer formation on the on the surface as shown in Table 2. For 500s, in the case of PS-THF system, $9.09 \%$ of the residual solvent remained for 967 micron thickness, as comparatively thinner coating retain less amount of the residual solvent $4.74 \%$ for 559 micron thickness and PMMA-EB system, 972 micron coating thickness retained $93.10 \%$ and 404 micron thicknesses retained $82.35 \%$ residual

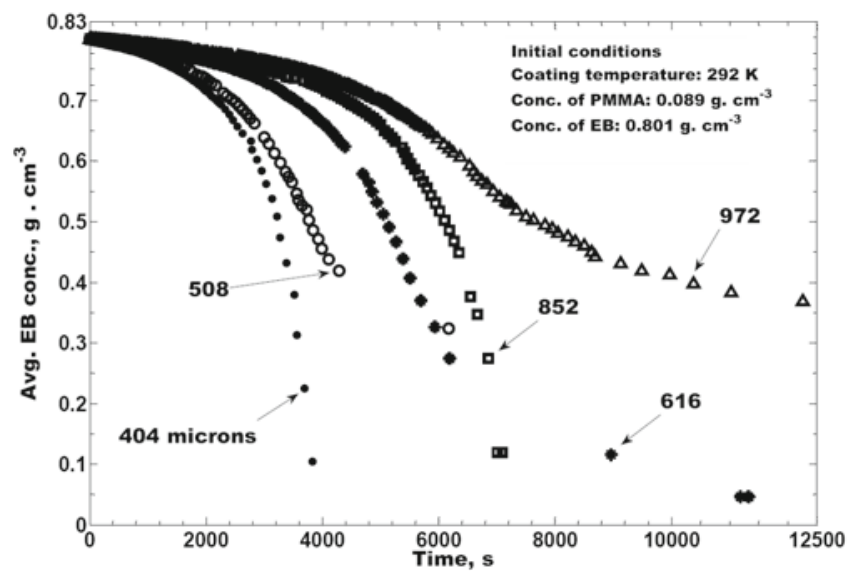

Figure 4b. Average concentration of EB with time in PMMA-EB coating

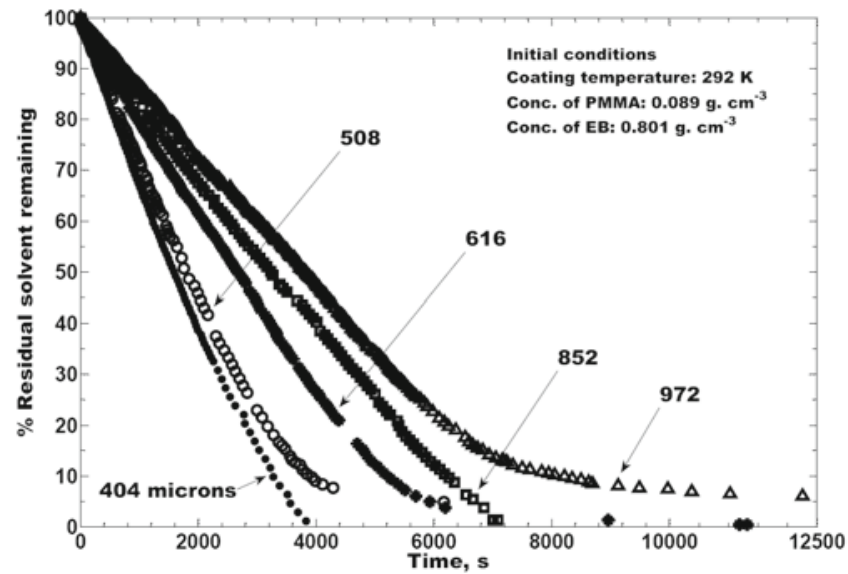

Figure 4c. Percentage residual solvent remaining with time in PMMA-EB coating

solvent. Similarly for PS-P-xylene system retained 93.10\% for 996 micron thickness as a thicker coating and thinner coating retained $90.50 \%$ for 592 micron thickness. PMMA-THF system retained $10.78 \%$ for thicker coating and thinner coatings retained $8.46 \%$ for $846 \mu \mathrm{m}$ and $565 \mu \mathrm{m}$ respectively.

The results reported in this work are in agreement with the earlier simulation studies, ${ }^{9,15}$. Khandelwal et

Table 2. Percentage residual solvent as function of thickness

\begin{tabular}{|c|c|c|}
\hline System & Coating Thickness, $\mu m$ & $\%$ of Residual solvent \\
\hline \multirow{2}{*}{ PS - THF } & 967 & 1.502 \\
\cline { 2 - 3 } & 559 & 0.285 \\
\hline \multirow{2}{*}{ PMMA - EB } & 972 & 5.2623 \\
\cline { 2 - 3 } & 404 & 1.1185 \\
\hline \multirow{2}{*}{ PS - p-xylene } & 996 & 4.561 \\
\cline { 2 - 3 } & 592 & 1.327 \\
\hline
\end{tabular}

Table 3. Effect of solvent molecular weight on the residual solvent remaining

\begin{tabular}{|l|c|c|c|c|}
\hline System & $\begin{array}{c}\text { Molecular } \\
\text { weight of } \\
\text { polymer, } \\
\text { g.mol }\end{array}$ & $\begin{array}{c}\text { Molecular } \\
\text { weight of } \\
\text { solvent, } \\
\text { g.mol }\end{array}$ & $\begin{array}{c}\text { Coating } \\
\text { thickness, } \\
\mu m\end{array}$ & $\begin{array}{c}\% \text { of } \\
\text { Residual } \\
\text { solvent }\end{array}$ \\
\hline PS - THF & 192000 & 72.11 & 967 & 1.502 \\
\hline $\begin{array}{l}\text { PS - } \\
p-x y l e n e\end{array}$ & 192000 & 106.16 & 996 & 4.561 \\
\hline $\begin{array}{l}\text { PMMA - } \\
\text { THF }\end{array}$ & 120000 & 72.11 & 846 & 3.303 \\
\hline $\begin{array}{l}\text { PMMA - } \\
\text { EB }\end{array}$ & 120000 & 106.17 & 852 & 5.792 \\
\hline
\end{tabular}


al. ${ }^{15}$ have performed an extensive simulation study to see the effects of coating thickness, oven temperatures, top and bottom air flow rates and the amount of polymer in the coating. They have concluded that thicker coatings should be dried at low temperature to minimize the residual solvent within the coating to avoid boiling of the coating. The residual solvent increases with an increase in the coating thickness.

\section{CONCLUSIONS}

The effect of the coating thickness has been investigated for PS-THF, PS- $p$-xylene, PMMA-THF and PMMA-EB coatings. The result shows that thicker coating will retain a higher amount of residual solvent compared to thinner coatings. Higher molecular weight solvents and polymers result in the higher amount of the residual solvent due to a low diffusion coefficient within the coating. Higher molecular weight solvent will retain a higher amount of the residual solvent.

\section{LITERATURE CITED}

1. Arya, R.K. (2010), Drying of Thin Film Polymer Coating: Theories, Experiments and Optimization, Ph.D. Thesis, Indian Institute of Technology Bombay, India.

2. Vrentas, J.S. \& Duda, J.L. (1977),Diffusion in Polymer-Solvent Systems I. Rexexamination of the Free-Volume theory, Journal of Polymer Science: Polymer Physics Edition, 15, 403-416. DOI: 10.1002/pol.1977.180150302.

3. Vrentas, J.S. \& Duda, J.L.(1977), Diffusion in Polymer-Solvent Systems II. A Predictive Theory for the Dependence of Diffusion Coefficients on Temperature, Concentration and Molecular Weight, Journal of Polymer Science :Polymer Physics Edition, 15, 417-439. DOI: 10.1002/pol.1977.180150303.

4. Izzo, C. (1991),How Are Coatings Applied, in Products Finishing Directory, Gardner Publication, Cincinnati, Ohio.

5. Barttfeld, M., Alleborn, N. \& Dusrt, F. (2006),Dynamic optimization of multiple-zone air impingement drying processes, Computers \& Chemical Engineering, 30, 467-489.

6. T., Y.O. \& Drake, R.L. (1990),Heat and Mass Transfer during Evaporation in Coating Formation, Journal of Colloid and interface Science, 135, 562-572.

7. Vadapalli, V.(2001), Simplified Method for Predicting Residual Solvent Content in Polymer Coatings, Master Thesis, Drexel University.

8. Gutoff, E.B. \& Cohen, W.D., 1996, "R\&D needs in the drying of coatings", Drying Technology, 14(6), 1315-1328. DOI:10.1080/07373939608917148.

9. Price, P.E. Jr. \& Cairncross, R.A. (2000), Optimization of Single-Zone Drying of Polymer Solution Coatings using Mathematical Modeling, Journal of Applied Polymer Science, 78, 149-165. DOI: 10.1002/1097-4628(20001003)78:1<149::AID-APP190>3.0.CO;2-Y.

10. Alsoy, S. \& Duda, J.L. (1998), Drying of Solvent Coated Polymer Films, Drying Technology, 16(1), 15-44. DOI:10.1080/07373939808917390.

11. Alsoy, S. (2001), Predicting Drying in Multiple - Zone Ovens, Industrial \& Engineering Chemistry Research, 40(14), 2995-3001. DOI: 10.1021/ie000751+.

12. Cairncross, R.A., Jeyadev, S., Dunham, R.F., Evans, K., Francis, L.F. \& Scriven, L.E., (1995), "Modeling and Design of An Industrial Dryer With Convective and Radiant Heating", Journal of Applied Polymer Science, 58, 1279-1290.

13. Price Jr., P.E. \& Cairncross, R.A. (1999), Optimization of Single-Zone Drying of Polymer Solution Coatings to Avoid Blister Defects, Drying Technology, 17(7), 1303-1311. DOI:10.1080/07373939908917616.
14. Ramesh, N. \& Duda, J.L. (2001), Analysis of Gap Dryer Used to Produce Polymer Films and Coatings, AICHE J., 47(5), 972-983. DOI: 10.1002/aic.690470504.

15. Khandelwal, A., Singhania, M. \& Vinjamur, M. (2009), Optimization of Operating Conditions in a Single-Zone Drier for Two-Layer Polymer Coatings, Journal of Applied Polymer Science, 111(1), 308-316. DOI: 10.1002/app.29105.

16. Vrentas, J.S. \& Duda, J.L. (1977), Diffusion in Polymer-Solvent Systems. III.Construction of Deborah Number Diagrams, Journal of Polymer Science: Polymer Physics Ed., 1977, 15, 441-453. DOI: 10.1002/pol.1977.180150304.

17. Hong, S.U. (1995), Prediction of Polymer / Solvent Diffusion Behavior Using Free - Volume Theory, Industrial and Engineering Chemistry Research, 34, 2536-2544. DOI: 10.1021/ ie9605286.

18. Alsoy, S. \& Duda, J.L. (1999), Modeling of Multicomponent Drying of Polymer Films, AICHE Journal, 45, 4, 896-905. DOI: $10.1002 /$ aic.690450420. 